\title{
AMBIGUIDADES E DESAFIOS DA DECISÃO (JUDICIAL) DE INTERVENÇÃO JUNTO AOS HOMENS AUTORES DE VIOLÊNCIA CONTRA MULHERES
}

Anderson Eduardo Carvalho de Oliveirai

Mariana Thorstensen Possasii

\section{RESUMO}

A lei Maria da Penha, em sua redação original, previu a possibilidade de criação de "centros de educação e de reabilitação para os agressores". Porém, a implementação desses mecanismos ainda está muito aquém das necessidades registradas. Não há consenso sobre a importância de se investir na execução de trabalhos junto a homens autores de violência, estabelecendo-se, muitas vezes, um debate polarizado entre os diversos atores sociais. Neste artigo, buscamos identificar os argumentos mobilizados para justificar a implementação dos serviços, bem como aqueles que funcionam como obstáculos, partindo da análise de documentos e catorze entrevistas realizadas com colaboradoras/es que se autodeclararam feministas ou pró-feministas e que participaram em atividades de formulação e monitoramento da lei Maria da Penha e/ou nos trabalhos de implantação e implementação dos serviços de responsabilização e educação no país. Ao final, destacamos a importância do enfrentamento efetivo deste debate na esfera pública, a fim de contribuir para a consolidação de uma política nacional de atenção a homens autores de violência doméstica contra as mulheres.

PALAVRAS-CHAVE: violência doméstica; lei Maria da Penha; políticas públicas; serviços de responsabilização e educação.

' Universidade Federal da Bahia, Faculdade de Filosofia e Ciências Humanas, Salvador, BA, Brasil, ORCID; ii Universidade Federal da Bahia, Faculdade de Filosofia e Ciências Humanas, Salvador, BA, Brasil, ORCID. 


\title{
AMBIGUITIES AND CHALLENGES OF THE (JUDICIAL) INTERVENTION DECISION WITH MEN WHO HAVE UDES VIOLENCE AGAINST WOMEN
}

\author{
Anderson Eduardo Carvalho de Oliveira \\ Mariana Thorstensen Possas
}

\begin{abstract}
The Maria da Penha law, already in its original wording, foresaw the possibility of creating "education and rehabilitation centers for aggressors". However, the implementation of these mechanisms is still below registered needs. There is not even a consensus on the importance of investing in the execution of work with men who commit violence, often establishing a polarized debate between different segments and social actors. In this article, we seek to identify the arguments used to justify the implementation of the services, as well as those that present themselves as obstacles, starting from the analysis of documents and fourteen interviews with collaborators who declared themselves to be feminists or profeminists and who participated in activities formulation and monitoring of the Maria da Penha law and/or in the implementation of accountability and education services in the country. In the end, we highlight the importance of effectively confronting this debate in the public sphere, in order to contribute to the consolidation of a national policy of care for men who commit domestic violence against women.
\end{abstract}

KEYWORDS: domestic violence; Maria da Penha law; public policy; accountability and education services. 


\section{INTRODUÇÃO}

A lei Maria da Penha representou um grande avanço para o enfrentamento da violência doméstica e familiar contra as mulheres no Brasil. Reconhecendo ser este um problema multifacetado, buscou tratá-lo de forma integral, oferecendo uma série de instrumentos que possibilitam a prevenção, a proteção e a assistência das mulheres em situação de violência, além de abrir espaço para o debate sobre a responsabilização daqueles que a praticam. Isto porque, já em sua redação original, previu a possibilidade de criação de "centros de educação e de reabilitação para os agressores". Recentemente, a lei n 13.984/2020 ainda ampliou o rol das medidas protetivas de urgência para incluir o encaminhamento obrigatório e o atendimento psicossocial - individual ou em grupo - para esses sujeitos.

A implementação desses mecanismos entretanto ainda está bem aquém das necessidades registradas. Não há nem mesmo consenso sobre a importância do investimento na execução de trabalhos junto a homens autores de violência, o que produz, muitas vezes, um debate polarizado entre diversos segmentos e atores sociais.

Neste artigo, fruto de uma pesquisa de doutorado, financiada com recursos da Coordenação de Aperfeiçoamento de Pessoal de Nível Superior (CAPES) do Ministério da Educação (MEC), buscamos identificar os argumentos mobilizados para justificar a implementação desses serviços, a partir de 14 entrevistas semidiretivas e semiestruturadas, realizadas entre os anos de 2016 e 2018, com colaboradoras/es que se autodeclararam feministas ou pró-feministas e que participaram em atividades de formulação e monitoramento da lei Maria da Penha

\footnotetext{
1 encaminhamento obrigatório dos homens autores de violência aos serviços de responsabilização e educação já estava previsto no artigo 152 da lei de execução penal, com a redação dada pelo artigo 45 da lei Maria da Penha. Porém, tal dispositivo se refere aos casos de imposição de pena restritiva de direito de limitação de fim de semana, que consiste na determinação de o apenado ser recolhido à casa de albergado, por 5 horas diárias aos sábados e domingos, onde pode ser submetido a cursos, palestras e outras atividades de cunho educativo. Com a nova redação dada pela lei $n^{\circ} 13.984 / 2020$, o encaminhamento enquanto medida protetiva de urgência pode ser decretado a qualquer momento, desde a etapa da investigação até a fase processual.
} 
(grupo 1) e/ou nos trabalhos de implantação e implementação dos serviços de responsabilização e educação para homens autores de violência no país (grupo 2).

As/os entrevistadas/os são identificadas por códigos iniciados pela letra A quando se trata de participante do grupo 1 - ou B - nos casos de participantes do grupo 2, seguido de um número de ordem, estabelecido com base na data de realização da entrevista. Agrupar as/os interlocutoras/es nessas duas categorias tem a função de caracterizar o lugar de fala desses sujeitos, não sendo objetivo do trabalho estruturar a análise de modo comparativo, estabelecendo como esses lugares podem (ou não) distanciar/aproximar seus pontos de vista, embora isso não seja impossível de acontecer em algum momento.

Além disso, analisamos um conjunto composto por 7 documentos, de natureza pública e privada, que foram coletados durante a pesquisa de campo. Tratam-se de diretrizes e parâmetros técnicos construídos para nortear o desenvolvimento de ações junto a homens autores de violência, bem como mapeamentos das experiências já executadas no país. O único documento de natureza privada consiste em anotações de um participante do workshop realizado pela Secretaria de Políticas para as Mulheres da Presidência da República (SPM/PR) que culminou na elaboração das primeiras diretrizes propostas por aquele órgão². Esses documentos nos ajudaram a refletir sobre os desafios de várias ordens à implementação dos serviços de responsabilização para homens autores de violência no Brasil.

Ao lado de problemas relativos à falta de recursos, à pouca atenção ou mesmo à resistência de grupos políticos, identificamos também uma dimensão relativa à construção dos sentidos sobre a intervenção junto a homens. As entrevistas mostram uma ambiguidade sobre a relevância do serviço, especialmente no que toca à sua (in)adequabilidade à função de punir.

\footnotetext{
2 Durante os dias 3 e 4 de julho de 2008, a SPM/PR executou o workshop Discutindo os centros de educação e reabilitação para os agressores. Sediado na cidade do Rio de Janeiro, o evento reuniu diversos profissionais, acadêmicos e representantes da sociedade civil organizada. O produto dessas discussões foram sintetizados em uma publicação daquele órgão, em 2011, intitulado Diretrizes para implementação dos serviços de responsabilização e educação dos agressores.
} 
No roteiro de entrevista, construímos a seguinte questão para as/os colaboradoras/es: "para o/a senhor/a, quais os principais argumentos que são dados - ou que poderiam ser formulados - a favor da implementação desses serviços?" Não houve ninguém que explicitamente discordou da oferta dos serviços. A concordância, por sua vez, se expressou em diferentes gradações, mostrando resistências de diferentes naturezas ao serviço.

\section{ARGUMENTOS DE INCENTIVO}

Os argumentos favoráveis à implementação dos serviços podem ser agrupados em dois grupos distintos, à medida que se aproximam ou se afastam das expectativas de aplicação do direito penal. Na esfera penal, destaca-se o diagnóstico de falência do sistema prisional e a ineficácia das medidas punitivas tradicionais, enquanto que na esfera não penal se evidenciam a natureza relacional do fenômeno e as ambiguidades dos sentimentos envolvidos nas relações domésticas e familiares.

\section{FALÊNCIA DO SISTEMA PRISIONAL E INEFICÁCIA DAS MEDIDAS PUNITIVAS TRADICIONAIS}

Identificamos um ponto de convergência total entre as/os participantes da pesquisa para justificar a oferta dos serviços de responsabilização e educação para os homens autores de violência contra as mulheres: a falência do sistema prisional e a ineficácia das medidas meramente punitivas.

É farta a literatura acadêmica que aponta como a prisão se transformou numa experiência falha, com resultados inexpressivos para o enfrentamento da criminalidade como um todo. Para Salla e Lourenço (2014) "as prisões têm se mostrado incapazes de operar uma transformação moral nos indivíduos para melhor acomodá-los dentro da sociedade" (p. 378). Baratta (2011) diz que "os institutos de detenção produzem efeitos contrários à reeducação e à reinserção do condenado, e favoráveis à sua estável inserção na população criminosa" (p. 183). 
Além de seus efeitos estigmatizantes, o ambiente carcerário se impõe como um campo disciplinar, de tom repressivo e uniformizante, opondo-se, assim, ao ideal educativo que pressupõe sentimentos de liberdade e espontaneidade do indivíduo. Neste ambiente hostil e degradante, os sujeitos são submetidos a um processo de socialização que, por um lado, afasta-os cada vez mais dos valores e modelos comportamentais instituídos para a vida em liberdade; e, por outro, incorporam os padrões alimentados pela subcultura carcerária, colocando em xeque qualquer ideal ressocializador ou reeducativo.

Em sentido mais amplo, alguns autores caracterizam o que vivemos no Brasil como "uma profunda e grave crise de legitimidade do sistema penal" (Andrade, 1999, p. 106), teórica e empiricamente evidenciada pelo descumprimento de suas promessas mais fundamentais: a proteção dos bens jurídicos de interesse geral; o enfrentamento da criminalidade por meio da retribuição e da prevenção geral e especial; e a aplicação igualitária das penas. Essa perspectiva é partilhada, de maneira unânime, pelas/os interlocutoras/es da pesquisa, podendo ser expressa com a expressão "entra ruim, sai pior".

[...] todo mundo que entra, sai pior do que entrou. Então, eu não acho que a prisão seja uma solução e eu acredito que até para as outras questões eu sou contra a prisão. Eu acho que, por mim, não existiria prisão. Tinha que ter outras formas de punição e de trabalho efetivo. (B2).

Aí eu vou lá e te prendo. Aí o homem aprende mais coisas criminalizantes lá, enfim, lá na prisão. Aí eu fico mais puto com o sistema, vou lá e bato mais na mulher e digo que as mulheres são todas loucas, putas, que botam a gente na prisão. Qual o efeito disso? Esse é o efeito direto de uma penalização, que acaba sendo contrário. Mantém uma guerra entre os sexos, deixam os caras mais putos, mais raivosos, saindo mais agressivos, mais agressores. (B3).

Pesquisadores/as, políticos e outros atores sociais constantemente ressaltam as altas taxas de reincidência entre os sujeitos condenados para reafirmar a tese de falência do sistema prisional e ineficácia das medidas punitivas 
tradicionais. Nas duas últimas décadas do século passado e nos primeiros anos do atual, os trabalhos mais citados acerca da reincidência criminal foram os produzidos por Adorno e Bordini (1989; 1991) e Kahn (2001), ambos sobre o estado de São Paulo; e o de Lemgruber (1989), focalizando a realidade do estado do Rio de Janeiro. Em 2008, o sistema carcerário nacional virou pauta para uma Comissão Parlamentar de Inquérito - CPI na Câmara dos Deputados (2009), cujo relatório final, citando dados de um relatório de gestão do Departamento Penitenciário Nacional (DEPEN), divulgou que a taxa de reincidência no país era de $70 \%$, podendo chegar a $80 \%$ em algumas unidades da federação. Com isso, ajudou a consolidar "uma percepção generalizada, e fomentada em boa medida pelos profissionais da segurança pública, de que boa parte da criminalidade que aflige a sociedade brasileira é oriunda de criminosos reincidentes." (Sapori; Santos \& Maas, 2017, p. 1).

Mais recentemente, a pesquisa Reincidência criminal no Brasil (Instituto Econômico de Pesquisa Aplicada [IPEA], 2015) revelou que 24,4\% dos excondenados, portanto, aproximadamente um a cada quatro, reincide na prática delitiva. Para tanto, leva em consideração apenas as hipóteses que se amoldam ao conceito de reincidência legal previsto no Código Penal brasileiro, ou seja, quando o indivíduo experimenta nova condenação em um período de até cinco anos após o cumprimento da pena anterior.

No entanto, este não é o único conceito válido de reincidência, tampouco é o que melhor traduz a realidade ${ }^{3}$. Quando essas outras formas de compreendê-la são utilizadas, o percentual observado cresce sensivelmente. É o caso do trabalho desenvolvido por Sapori, Santos e Maas (2017), no estado de Minas Gerais, que, ao utilizar como critério um ou mais indiciamentos do indivíduo após o cumprimento da pena ou recebimento da liberdade condicional, descobriu que mais da metade da população carcerária volta a praticar crimes após deixar o sistema penitenciário.

\footnotetext{
3 O conceito de reincidência pode ser colocado e empiricamente operacionalizado de quatro formas distintas: a) reincidência natural ou genérica, quando o sujeito incide na prática de novo ato criminoso, independentemente de uma condenação anterior; b) reincidência social, no caso de já existir condenação anterior, ainda que não cumprida no sistema prisional; c) reincidência penitenciária, caracterizada por uma nova passagem pelo sistema carcerário; e d) reincidência legal, conforme definição trazida no corpo do texto (Adorno \& Bordini, 1989).
} 
Por outro lado, alguns estudos têm sinalizado para um nível mínimo de reincidência na prática de violência contra mulheres entre os homens que são encaminhados para os serviços de responsabilização e educação, como expresso por um colaborador para apresentar a oferta dos serviços como um mecanismo alternativo e mais efetivo para o enfrentamento do problema.

O Brasil já é o quarto país que mais tem pessoas presas, né? O sistema prisional ele tem uma reincidência de $80 \%$. De quase todos os homens que vão presos uma vez, 80\% voltam a ser preso novamente. E esse trabalho no grupo de homens a reincidência que a gente tem em pesquisa é de $5 \%$. Então, só 5\% dos homens que, no total que frequenta esse grupo, só 5\% volta a reincidir, volta a cometer violência contra a mulher. Então, ele consegue efetivamente romper com a questão da violência. (B2).

Ainda que os dados de reincidência apresentem fragilidades como marcadores de efetividade, principalmente se usados de forma isolada, além do fato de serem muitas vezes divulgados por quem está diretamente interessado na execução dos serviços, é possível encontrar na literatura científica brasileira alguns estudos que corroboram essa fala, indicando baixos índices entre homens que participaram de programas e serviços dessa natureza (Teixeira \& Maia, 2001; Andrade \& Barbosa, 2008). Na literatura internacional, analisando dados de serviços na América do Norte, Taylor e Barker (2013) sinalizam para uma taxa média recidiva na ordem de $32 \%$ entre os homens que concluíram a participação e de $46 \%$ nos casos em que a programação não foi concluída, conforme relatado por suas próprias companheiras. No mapeamento espanhol, a taxa de reincidência é apresentada no patamar de 22\% (Beiras, Nascimento \& Incrocci, 2019).

Em desfavor das medidas punitivas pesa ainda o fato de que, dentre os valores partilhados pela população carcerária, destacam-se elementos constitutivos da masculinidade hegemônica, por exemplo, a virilidade e a agressividade. De tal modo, "ao confinar os homens justamente onde impera a virilidade violenta como linguagem de sobrevivência, estaremos apenas 
amplificando os dispositivos que ajudam a consolidar o amálgama masculinidadeviolência" (Mourão, 2014, p. 290). Logo, o cerceamento da liberdade do indivíduo que incide na prática de violência contra as mulheres promoveria apenas a repressão e, quando muito, a sua contenção temporária. Mas, não é apto a promover uma ruptura com os valores patriarcais e, via de consequência, o reconhecimento das mulheres como sujeitos de direitos.

O comportamento violento se processa com base nas percepções que temos de nós mesmos e pela forma como percebemos o outro (Mourão, 2014). Por conta disso, qualquer estratégia de controle apenas experimentará resultados positivos se levar em conta duas ordens de fatores: a subjetividade e os recursos de comunicação, que garantem a escuta e o reconhecimento das demandas do outro, bem como da sua condição de sujeito, sem desprezar necessidades próprias. "Pela mera repressão pode-se, na melhor das hipóteses, alcançar pacificações artificiais, camuflando temporariamente violências que irão eclodir, no futuro, em outras áreas ou relações" (Mourão, 2014, p. 290).

O sistema penal, salvo raras exceções, não apresenta uma forma eficiente de proteção das mulheres em situação de violência e, ainda, duplica a vitimização na medida em que as expõe a uma violência institucional plurifacetada do próprio sistema (Andrade, 1999). Por outro lado, ao mesmo tempo em que se argumenta pela falência do sistema prisional, alimenta-se a ideia de insuficiência das medidas punitivas tradicionais e a importância do trabalho reflexivo com homens autores de violência. Nas falas das/os interlocutoras/es:

Não adianta você punir se não tiver um tratamento para o cara entender; para ver; para reconhecer a questão; para repensar e reabilitá-lo; para se reintegrar na família. Eu acho que o que foi pensado [serviços para os autores] é importante. Você tem que fazer um trabalho, porque não adianta punir. O cara vai sair de lá e vai fazer de novo se você não tiver um trabalho com ele. (A1).

[...] simplesmente punir esses autores de violência com uma pena, uma resposta tradicional da justiça, isso é absolutamente insuficiente para 
combater a violência contra a mulher [...] se a gente está lidando com a violência contra a mulher como um problema social, estrutural, a violência baseada no gênero, a gente só vai conseguir ter algum caminho de superação desse problema se a gente conseguir modificar essa estrutura de relação na sociedade. E para modificar essa estrutura de relação na sociedade a gente tem que passar pelas medidas que envolvam aí uma educação para uma nova visão de gênero, para uma nova relação de gênero. (B4).

Essas especificidades da violência baseada no gênero, principalmente por seu componente cultural, elucidam ainda a insatisfação registrada por parte das/os colaboradoras/es com as propostas de resposta penal construídas a partir do prefixo "re": reeducação, reabilitação, ressocialização, recuperação etc., todas elas reproduzidas no próprio texto da lei Maria da Penha.

Eu acho que qualquer possibilidade de reabilitação, de ressocialização, qualquer "re", PÉSSIMO! Totalmente PÉSSIMO. Então, eu já não proporia nada nesse sentido. [...] eu acho que qualquer "re" nesse negócio é ridículo. (A6).

Quando usamos esses vocábulos, indicamos um movimento de resgate de competências e preceitos que se tinha e que foram, em algum momento e por algum motivo, abandonados. Porém, não se perde aquilo que não se tem. "A desigualdade de gênero aparece em toda as fases da socialização, primária e secundária, e, sendo assim, precisa ser conhecida e desconstruída e passar por processo de educação, e não por reabilitação ou reeducação" (Andrade, 2014, p. 84). Por isso, inclusive, as experiências brasileiras carregam prioritariamente em seus títulos a ideia de responsabilização e educação.

\section{NATUREZA RELACIONAL DO FENÔMENO}


Considerando o caráter relacional da violência doméstica e familiar contra as mulheres e sua multicausalidade, as/os convidadas/os mobilizaram argumentos que rompem com a lógica tradicional e reducionista do direito penal para justificar a oferta de serviços para homens autores de violência.

A gente já tem capacidade teórica para superar essa visão mais curta, digamos assim, de não entender a importância de que a violência não é uma questão unilateral. Ela é uma relação e não adianta trabalhar só com um lado. A gente vai, tudo bem, oferecer para essa mulher a possibilidade de sair de uma outra relação, mas esse sujeito não vai mudar o seu comportamento. Então, é importante, se a gente quer ter uma outra relação de sociabilidade entre homens e mulheres, bom, homens e mulheres têm que refletir sobre os seus comportamentos. (A6).

Tu tem que ver tudo que está envolvido. Aí entra a questão da visão holística, não é? Tu ter uma política pública que ela consiga capturar todas as fases do mesmo fenômeno, que todos os fenômenos eles são multifatoriais. Eles são frutos de diferentes fatores. Então, não adianta você focar um negócio só, porque tu não vai conseguir eliminar nunca. (A3).

Sujeitos pertencentes ao segundo grupo de entrevistadas/os (que se vinculam aos processos de implantação e implementação dos serviços) manifestam preocupação com o sofrimento dos homens e a necessidade de cuidado, em reconhecimento aos males que Ihes são infligidos no exercício da masculinidade hegemônica. Assim, diferente do que ocorre com as medidas punitivas, pelas quais a "vítima ganha o que o agressor perde", o encaminhamento para os grupos reflexivos ofereceria a possibilidade de outra lógica, em que todos/as saem ganhando.

Quando eles conseguem perceber que eles praticam violência, sofrem. Tem homem que fica triste. Eles saem da raiva. Eles entram no medo [...] Os 
homens não conversam sobre isso. Então, quando eles falam: 'vamos sair por aí pegando geral' - quando não falam isso de uma forma bastante pejorativa: 'vamos sair por aí pegando um monte de bucetinha'; ou 'vamos encher a cara'. Isso quando o cara se separou, está com dor, triste, precisa falar da tristeza, do sofrimento, ao menos ter a companhia para alguém ficar ali do lado, respeitando isso. (B7).

[...] a gente pode pensar que ele está sendo cuidado. Está. E é muito bom ele ser cuidado para ele cuidar melhor também. Então, tem uma função na qualidade de vida dele, que ele melhorando as relações, ele vendo as possibilidades de se relacionar de forma não tão em cima de uma masculinidade hegemônica, ele tem ganhos. Porque ele vai poder lidar com o outro com mais sentimentos. Ele aqui tem a possibilidade de chorar, de lidar com os afetos, de lidar com a paternidade. (B1).

São dois os pressupostos que se pode perceber em decorrência dessas falas: a) se o processo de socialização apresenta níveis de toxicidade para os próprios homens, acredita-se que, nesses grupos, eles podem partilhar de seus sofrimentos e angústias. Este é o fio condutor para o abandono dos valores patriarcais e a transformação de suas relações, consigo e com o outro, de modo a se tornarem mais sadias; e b) essa transformação é possível porque a etiqueta de "agressor" não é vista como conformadora de uma identidade, senão um estado transponível. Não à toa, as intervenções registradas no país tem feito uso prioritário da expressão "homens autores de violência".

Como defendem estudiosas/os da temática, ninguém permanece no lugar de "agressor" ininterruptamente. "Temos de reconhecer que a agressão é desencadeada por diversos estímulos e que, na sua maioria, não determina a identidade de uma pessoa" (Andrade, 2014, p. 182). Além disso, a noção de agressividade é compreendida como uma força biopsicológica, geralmente utilizada para satisfazer necessidades vitais e não para o exercício do controle do outro. Ao usarmos a palavra "agressor", estaríamos a reduzir o comportamento 
violento dos homens ao campo biopsicológico e intrapsíquico, colocando-o como uma tendência ou predisposição (Acosta, Andrade Filho \& Bronz, 2004).

\section{AMBIGUIDADES DA FIGURA DO PAI DE FAMÍLIA AGRESSOR}

Sendo "agressor" um estado temporário do sujeito, as situações de violência doméstica e familiar nos remetem para um cenário marcado pela ambiguidade de sentimentos. Decorre daí o terceiro conjunto de argumentos favoráveis à oferta dos serviços e que se distancia do modelo de punição oferecido pelo direito penal, compartilhado pela quase totalidade das/os entrevistadas/os, independente do grupo a que pertença: as medidas exclusivamente punitivas não constituem a resposta esperada pela maioria das mulheres.

Vários estudos mostram que muitas mulheres acabam retirando a queixa ou não querem levar adiante os processos porque elas não querem a punição dos caras, assim presos, né? Criminalizar. Querem só que eles levem um sabão, que não voltem a fazer mais. (A1).

Eu diria que vem das próprias mulheres em situação de violência, que a maioria delas não quer que os seus maridos sejam presos, os pais dos seus filhos sejam presos. Muitas delas verbalizam isso. Vários estudos nos dão isso numa dimensão muito significativa. (A3).

Pesquisa realizada pelo Ministério da Justiça (2015) indicou que dentre as mulheres que acessam as varas especializadas de violência doméstica e familiar, apenas $20 \%$ expressam o desejo de que seus algozes, com quem elas mantêm ou mantiveram relações de afeto, sejam condenados a uma pena privativa de liberdade. A imensa maioria (80\%) sinaliza para a aplicação de medidas alternativas à prisão, como encaminhamentos a grupos reflexivos, atendimentos psicossociais ou prestação de serviços à comunidade. 
Mais recentemente, pesquisa desenvolvida pelo Fórum Brasileiro de Segurança Pública (FBSP) e pelo Instituto Datafolha (2019) revela que a maior parte das mulheres em situação de violência (52\%) sequer tomou alguma providência diante das ocorrências. Das que agiram, somente $22,2 \%$ dizem ter procurado um órgão oficial, sendo $18,3 \%$ o percentual de mulheres que afirmaram ter feito a denúncia em delegacia (especializada ou não), configurando o primeiro passo para a persecução da responsabilização criminal. Outros 29,6\% tentaram auxílio junto à família, aos amigos ou à igreja.

Há uma série de fatores que devemos levar em consideração para interpretar esses números: o desconhecimento acerca da dinâmica de funcionamento do sistema de justiça criminal; a morosidade e a descrença em sua atuação efetiva para a garantia dos seus direitos fundamentais; ou mesmo o desejo de não ver seus companheiros ou ex-companheiros submetidos ao cárcere. Neste caso, não apenas pela condição de vulnerabilidade à violência estatal a que eles estarão expostos, mas sobretudo pelos reflexos econômicos e emocionais desse encaminhamento. São essas últimas as principais justificativas apresentadas pelas/os entrevistadas/os:

[...] as mulheres falam sobre os homens autores de violência, que dizem: 'ele é um ótimo pai; em alguns momentos ele é um ótimo amante; em outros momentos ele é ótimo companheiro. Tem momentos em que ele perde o controle e faz'. (B5).

É uma coisa um pouco diferente a coisa doméstica. O cara é o pai dos filhos. Ela casou com o cara. E ela não quer que ele seja punido, porque ele vai ser preso, vai atrapalhar, não vai ter renda. Repare: como vai ser para a família? Vai prejudicar a família, mas ela não quer que ele continue agressivo. Então, ele fazer o tratamento atende um pouco essa questão das demandas das mulheres. (A1). 
Faz-se, a partir daí, uma importante distinção entre os demais "clientes" do sistema prisional e os que lá chegam em virtude da prática de comportamentos que configuram violência doméstica e familiar contra mulheres. Ainda que não mobilizem necessariamente o binômio pai de família/vagabundo, como se observa no trecho a seguir, sempre marcam a distinção em termos de oposição ao infrator "comum", que é "desconhecido da vítima".

Então se você trabalha, traz dinheiro, põe a comida na mesa, você é visto como pai de família, mesmo que você seja um agressor da mulher. Então, as mulheres usam, trabalham com esse conceito e acabam, não sei se perdoando, mas não querendo que esse cara, que seja um pai de família, vá para o mesmo lugar que os vagabundos vão, que é a prisão. (A1).

Como se observou nos estudos sobre a falta de interesse das mulheres na representação criminal de seus algozes, popularizada pela expressão "desistência da queixa" (Jong, Sadala \& Tanaka, 2008; Souza, 2017), a dependência financeira, o afeto e a vontade de manter a unidade familiar também estariam por trás dos discursos de rechaço às penas de prisão. Portanto, ainda que caiba a problematização dos anseios expressados por essas mulheres e reflexões acerca do seu fundamental processo de empoderamento, colocar-se contrário à implementação dos serviços seria negar escuta aos reclamos das principais interessadas, que não demandam pela punição de seus algozes, mas sim pelo fim da violência em suas vidas por meio de outras ações e respostas.

\section{ARGUMENTOS QUE LEVANTAM OBSTÁCULOS}

Muitas falas levantaram as dificuldades ou obstáculos à implementação dos serviços. As objeções lançadas pelas/os colaboradoras/es gravitam em torno de dois eixos principais. O primeiro é de ordem político-financeira, que perpassa pela vontade política dos governos na implementação de políticas públicas para a igualdade de gênero, acompanhada de uma tensa disputa para o emprego dos 
poucos recursos disponíveis. O segundo é de cunho metodológico, reunindo argumentos que expressam críticas à efetividade dos serviços.

Identificamos ainda um terceiro eixo, menos central, mas que também funciona como obstáculo às intervenções junto a homens autores de violência no país. Este é de ordem "epistemológica" e diz respeito diretamente às dificuldades de inovação no campo do direito penal.

\section{VONTADE POLÍTICA E A ESCASSEZ DE RECURSOS}

A lei Maria da Penha não previu somente normas jurídicas que regulam a atuação do sistema de justiça e de segurança pública nos casos de violência doméstica e familiar contra mulheres. Ela também desafiou o estado brasileiro a promover uma política integrada e com abordagem multidisciplinar que, primando pela pluralidade de ações, fosse capaz de oferecer uma resposta adequada ao enfrentamento desta grave modalidade de violação aos direitos humanos. Portanto, a implementação integral da lei Maria da Penha é de responsabilidade do Estado, perpassando pela atuação dos variados governos, a quem compete realizar a administração dos recursos, bem como decidir quanto e em quais setores se deve investir.

Em uma estrutura estatal extremamente patriarcal, são grupos de homens, notadamente os que são identificados pelos signos da masculinidade hegemônica e pertencentes às classes sociais mais abastadas, que controlam a maior parte dos recursos necessários à implementação da agenda das mulheres para a garantia de seus direitos mais fundamentais (Connell, 2016). Não obstante o papel dos homens surgir de modo mais incisivo nos debates internacionais a partir da década de 19904, a viabilização prática desses pressupostos segue um grande desafio.

\footnotetext{
${ }^{4}$ Connell (2016) cita como exemplos a IV Conferência Mundial sobre a Mulher (Pequim/1995), que no parágrafo 25 de sua declaração indica que os governos se comprometam a "encorajar os homens a participarem plenamente de todos os atos favoráveis à igualdade"; e a Declaração Política da $23^{a}$ sessão especial da Assembleia Geral da Organização das Nações Unidas - ONU, ocorrida em 2000, ao consignar que "[os Estados-membros das Nações Unidas] enfatizam que homens devem se envolver e assumir responsabilidade conjunta com as mulheres para a promoção da igualdade de gênero."
} 
De modo geral, as/os interlocutoras/es acreditam que não há interesse por parte dos governos, sobretudo quando controlados por homens, para a implementação de políticas públicas para a igualdade de gênero, dentre as quais se inclui os mecanismos de enfrentamento à violência doméstica e familiar contra as mulheres, a exemplo dos serviços para homens autores de violência.

Eu acho que não tem interesse. As questões de gênero não interessam aos governos. Eles acham que isso não dá voto, entendeu? Não é um lugar de fácil manipulação. [...] Políticas de gênero não interessam. Não interessam porque, em princípio, ainda é coisa de mulher. Na verdade, ao implementar políticas de gênero, como elas vão tirar os homens, vão nos tirar da zona de conforto, podem encerrar os nossos privilégios. Por que eu vou fazer isso? Os homens querem abrir mão do privilégio? Eu hoje quero abrir mão desses privilégios porque entendi que não são privilégios. São camisas de força. Eu não quero ser miserável do ponto de vista emocional, do ponto de vista simbólico. Isso que o machismo faz, entendeu? Ficar obtuso, sabe? Mas, os homens acham que isso é ser bom. (B7).

Muitos homens não estão dispostos a abrir mão de seus privilégios ou sequer reconhecem a dimensão desse problema. Contudo, "se olharmos separadamente para cada uma das subestruturas de gênero, encontraremos um padrão de vantagens para homens, mas também um padrão vinculado de desvantagens ou de toxicidade" (Connell, 2016, p. 98). Se a socialização de gênero apresenta um lado perverso para os homens, principalmente os que destoam da cisheteronormatividade, é neste ponto que pode residir uma razão para a mudança de paradigma e engajamento de homens em prol da igualdade de gênero, qual seja: "evitar os efeitos tóxicos da ordem de gênero sobre eles." (Connell, 2016, p. 105).

A autora ainda destaca outros argumentos para se investir no engajamento dos homens para a igualdade de gênero. São eles: a) por serem sujeitos sociais, a sua qualidade de vida está diretamente relacionada com a qualidade das relações que estabelece com outros homens, mas também com mulheres, podendo assim 
falar em "interesses relacionais dos homens na igualdade de gênero"; b) as alterações nos papéis de gênero podem ser apoiadas com o despontar para a relevância do bem-estar coletivo, como, por exemplo, em matéria de segurança; e c) por entender que essas reformas decorrem de seus princípios políticos ou éticos, baseado na concepção de direitos humanos, amplamente reconhecida e legitimada (Connell, 2016).

Todavia, enquanto o engajamento de homens para a erradicação de seus privilégios, reformulação das masculinidades e construção da igualdade de gênero ainda for um projeto em curso, o que resta patente é que a participação das mulheres e dos movimentos feministas nos espaços de gestão é condição sem a qual não se vislumbra a implementação das políticas públicas de gênero, inclusive dos serviços para homens autores de violência. Conforme relatos das/os interlocutoras/es, a participação de mulheres feministas nas esferas governamentais é ponto crucial para a viabilização das principais experiências nesse campo no Brasil.

Se pega uma gestão que tem participação de mulheres feministas ou do movimento de mulheres, que está ligado aos movimentos de mulheres, que ouve o movimento de mulheres, acaba montando políticas nesse sentido. Agora se é uma gestão que não tem, não ouve essas questões de gênero, não tem proximidade com as questões de violência contra a mulher, então a pessoa nem sabe. (B2).

Há, precisamente, uma forte tendência em atribuir os avanços nesta área aos governos que se identificam à esquerda no espectro político, que estariam mais preocupados com a defesa dos interesses de grupos sociais mais vulneráveis e com a promoção da igualdade.

Onde você tem a maior ação hoje no Brasil é no ABC paulista. E por que é no ABC paulista? Porque naquele cinturão todo ali de São Paulo você tem os governos petistas, que de alguma forma as mulheres, as feministas dentro 
desses governos tiveram voz e conseguiram dizer. A gente precisou das mulheres para que a gente tivesse um trabalho no $A B C$, que é um trabalho que tem continuidade. (B7)

Primeiro, é que tem que ter uma vontade política no âmbito das políticas públicas. Primeiro, o que é que foi no Pará? Por que o Pará? Por que foi no Acre? Porque no Acre tinha um governador, que era aquele lá do PT, como é o nome? Chico não sei das quantas, um bem bonito por sinal, tá certo, de uma família de *. Tinha uma mulher que estava interessada, tinha uma atuação por parte do Estado quando o Estado pactuou com a Secretaria o combate à violência e cria aí uma grande parte de organismos, centros, delegacias etc. (A4)

Há, no estado brasileiro, uma tendência histórica de descaso com as políticas públicas de gênero. Mesmo nos governos em que se gozou de melhores condições, os recursos para sua implementação nunca foram suficientes. Ao analisarem o chamado Orçamento Mulher ${ }^{5}$, Souza e Vera (2010) observaram que os valores efetivamente repassados para as ações em favor dos direitos das mulheres inviabilizaram que elas fossem integralmente concretizadas. "As políticas que não são prioritárias ou não dispõem de garantias constitucionais, nem infra-legais, não são necessariamente executadas, mesmo que tenham sido previstas" (Souza \& Vera, 2010, p. 352).

Essas limitações orçamentárias sempre estiveram no cerne da discussão acerca da implementação dos serviços de responsabilização e educação, desde o momento de sua previsão na lei. A participação dos homens autores de violência em atividades educativas foi sugestão advinda de audiências públicas estaduais

\footnotetext{
5 O Orçamento Mulher é um instrumento desenvolvido pelo Centro Feminista de Estudos e Assessoria (CFEMEA) que permite monitorar o conjunto das despesas que atendem de forma direta ou indireta às necessidades específicas das mulheres, impactando nas relações de gênero e também de raça, previstas na Lei Orçamentária Anual. Sobre o assunto, ver, por exemplo, Vieira, Cabral e Oliveira (2014).
} 
realizadas durante o processo de discussão do projeto que culminou na lei Maria da Penha.

Muitas mulheres reivindicavam que fosse garantido aos agressores a possibilidade de frequentar os grupos de reflexão, durante o cumprimento da pena restritiva de direito, ou mesmo prestar serviços às organizações sociais que trabalham com homens agressores. (Cortês \& Matos, 2009, p. 48).

Por outro lado, grupos feministas diziam que a previsão de "centros de reeducação", penas alternativas ou justiça terapêutica provocariam a divisão dos recursos a serem destinados para as políticas voltadas às mulheres em situação de violência (Calasans \& Cortes, 2011).

Desde o início havia um preconceito de usar recurso que estavam sendo destinados para esse trabalho com mulheres, entendendo que esse trabalho com os homens eu estou passando a mão na cabeça dos homens e trabalhando em cima deles, quando na realidade esse recurso deveria ser usado para as mulheres. Aí de novo vem aquela briga entre homens e mulheres. (B3).

E nas audiências públicas eu acho que esse foi, ou pelo menos do que eu apreendi desse processo, foi um tema em que gerou muito debate justamente porque havia essa problematização de que ao incorporar à lei Maria da Penha esse mecanismo, você de alguma maneira vincularia isso às políticas de enfrentamento à violência contra a mulher e, consequentemente, vincularia a uma responsabilização do organismo de políticas para as mulheres, da SPM, de fazer a manutenção e bancar a existência desses serviços. Então, era uma leitura um pouco de que, tanto você criaria ali um caminho que faria ali uma distribuição dos recursos que já são escassos para promover políticas para as mulheres. Ao invés de você investir para as mulheres, para proteção e assistência etc., você investiria 
para os homens; como traria essa responsabilidade como um sobrepeso para as mulheres. Então, não basta serem as mulheres que têm que se preocupar com todo o resto, então elas ainda vão ter que se preocupar que esse serviço exista, que ele seja mantido e tal, e dar dinheiro para que a coisa exista. (B4)

Os serviços foram incorporados ao texto da lei Maria da Penha, mas a discussão em torno dos recursos seguiu latente, como ficou evidente na experiência do Serviço de Educação e Responsabilização para Homens Autores de Violência (SERH), inaugurado em 2008 na cidade de Nova Iguaçu-RJ.

Segundo Oliveira (2012), o serviço representou o maior esforço já empreendido no Brasil no que se refere ao atendimento a homens autores de violência contra mulheres, inclusive pelo montante de recursos empregados: $R$ \$ 1.112.283,66, sendo 90\% oriundos do Ministério da Justiça, através da Secretaria Nacional de Segurança Pública. Contudo, tal iniciativa não seria possível sem a articulação promovida pela SPM/PR, que se ocupou em definir uma agenda para viabilizar a criação desses serviços. A ideia era que o SERH pudesse servir de referência para futuros programas no país. O serviço, no entanto, encerrou suas atividades em novembro de 2009, por falta de novos recursos e de "vontade política". Ademais, segundo interlocutores daquela pesquisa, os debates para a renovação dos recursos foram marcados por tensões entre segmentos de movimentos feministas que questionavam a atuação da SPM/PR na consecução do serviço.

Setores dos movimentos feministas defendiam que as iniciativas de assistência às mulheres em situação de violência deveriam gozar de prioridade em relação ao atendimento aos autores. "Além disso, essa política deve fazer parte das políticas de segurança pública e de direitos humanos e não como responsabilidade dos organismos de políticas para as mulheres" (Cortês \& Matos, 2009, p. 48). Nossas colaboradoras também expressaram resistência em utilizar os recursos disponíveis com os homens agressores. 
[...] que era importante não tirar recursos de uma secretaria nova, com poucos recursos, mas sim usar recursos do Ministério de Justiça. Foi uma das lógicas e, assim, eu acho que faz sentido. (B5).

Concordo que o dinheiro não tem que vim das políticas para as mulheres, assim. Bom. Hoje a gente não tem orçamento nenhum. Mas, no momento em que a gente tinha um orçamento da SPM, eu concordo que o dinheiro para esse serviço não tinha que vim do orçamento da SPM para criação e manutenção. (B4).

Parte desta celeuma poderia ter sido superada com a edição da Portaria n. ${ }^{\circ}$ 216, de 27 de maio de 2011, do DEPEN, pela qual se estabeleceram os procedimentos e critérios para financiamento de projetos voltados à aplicação e execução de alternativas penais, principalmente de serviços de educação e responsabilização para homens autores de violência, com recursos do Fundo Penitenciário Nacional no exercício daquele ano. Embora algumas ações tenham emergido dali, as dificuldades para financiamento dos serviços persistem. A falta de uma política nacional que garanta recursos contínuos faz com que boa parte dos serviços executados fiquem à mercê da disposição política ou de parcerias viabilizadas por ONGS.

Para alguns das/os convidadas/os, as resistências aos serviços de responsabilização e educação para homens autores de violência foram superadas. O entendimento sobre a sua importância como mecanismo de enfrentamento à violência contra as mulheres foi sedimentado. O que se apresenta como verdadeiro obstáculo é, ainda, a carência de recursos:

Eu acho que esse momento da resistência foi um determinado momento. Hoje o que gente vê é o seguinte: enfim, o Estado - e eu vou falar mais especificamente do Judiciário, mas não só do Judiciário: as prefeituras, os governos estaduais. Na realidade, passados onze anos da Lei Maria da 
Penha6, eles não cumprem com a totalidade dos serviços. Os serviços de atenção psicossocial às mulheres ou aos familiares dessas mulheres em situação de violência não são prestados. (A5).

[...] eu acho que teve um momento assim, pela total (...) exatamente pela pressão feminista, da criação dos serviços e de focar nas mulheres. Eu acho que isso foi um momento do feminismo no Brasil. Criou os serviços, forçou a criação dos serviços e eu acho que é tudo processo da própria evolução do olhar, da perspectiva. Hoje, eu acho que dificilmente você vai encontrar feministas que sejam contra serviços para homens. pode dizer: 'não, se tem recursos vamos privilegiar as mulheres'. Mas, eu acho que a gente tem que olhar mais amplamente, né? Então, eu acho que dificilmente hoje alguém se coloca contra. Pode até ter, mas eu acho que é muito difícil. Porque já tem uma história, já tem estudos. Acho que está num outro momento. (A6).

Particularmente, entendemos que o debate não está totalmente superado. Mesmo defendendo a importância do serviço, o discurso em torno da escassez de recursos produz eco à ideia de que se deve priorizar o atendimento às mulheres em situação de violência. "Se você tem poucos recursos em um pequeno município, você vai usar esses poucos recursos para a mulher vítima ou para o homem autor?" (B5), questionou um deles durante a entrevista.

Com pouco, primeiro as pessoas que estão sofrendo, que precisam de um cuidado imediato, entendeu? Ainda mais que, se você não tiver, se os recursos são poucos, se for só a luta, vamos concentrar em dar apoio a essas mulheres porque estão vivendo em choque; estão vivendo uma situação mais complicada, embora eu ache que também tenha que ter esses serviços. (A1).

\footnotetext{
${ }^{6}$ Essa entrevista foi realizada em fevereiro de 2017 quando, portanto, havia passado um período de onze anos desde a promulgação da lei Maria da Penha.
} 
Há de se reconhecer que esse debate é extremamente sensível. Mas, quando colocado, fragiliza o entendimento acerca do caráter relacional do conceito de gênero e, consequentemente, da violência baseada no gênero. Essa leitura que contrapõe homens e mulheres para o estabelecimento de prioridades acerca do investimento de recursos, como acentua uma das entrevistadas: "é uma visão que não ajuda a mudar, digamos assim, o estado de coisas, as relações de sociabilidade violentas." (A6).

Essa leitura também parece impedir uma atuação mais incisiva de grupos de mulheres em pressionar o estado para que tal política seja incorporada de maneira efetiva e ainda são esses grupos os principais agentes no exercício da pressão para a incorporação das políticas públicas de gênero. No entanto, "enquanto a SPM prefere envolver-se apenas com programas dedicados ao atendimento às mulheres, o DEPEN ainda não prioriza as políticas de penas alternativas" (Amado, 2014, p. 41), de forma que os grupos para homens autores de violência continuam sendo um programa com impacto tímido na esfera nacional.

\section{DISPUTAS EM TORNO DA EXECUÇÃO DOS SERVIÇOS}

O reconhecimento da importância dos serviços somado à ausência do poder público nessa área abrem espaço para a atuação de outros setores da sociedade civil, não necessariamente preocupados com as causas feministas e as discussões teóricas propostas nos estudos de gênero. Desse modo, as experiências desenvolvidas no país assumem desenhos metodológicos diversos, gerando desconfiança entre as pessoas entrevistadas a respeito de quem se coloca diante da execução dos serviços e de quais técnicas mobilizam.

São recentes as tratativas do estado brasileiro para estabelecer os critérios de funcionamento desses serviços. A primeira consiste nas Diretrizes gerais dos serviços de responsabilização e educação do agressor, publicada em 2011 pela própria SPM/PR. O documento busca conceituar o serviço, traçar seus objetivos e 
pressupostos e estabelecer padrões para organização, estrutura, recursos humanos, avaliação e monitoramento, mas ainda de uma forma bastante rudimentar.

Em 2012, é publicado o Documento base para a elaboração de parâmetros técnicos para os serviços de educação e responsabilização de homens autores de violência doméstica contra as mulheres, elaborado pelo Ministério da Justiça em parceria com o Instituto de Estudos sobre a Religião (ISER), indicando as condições mínimas para a sua criação e manutenção, bem como as normas gerais para o atendimento a esses homens, muito próximo da experiência desenvolvida na cidade de Nova Iguaçu - RJ e aqui já mencionada.

Em 2016, o Ministério da Justiça lança um Manual de gestão para alternativas penais, dedicando uma parte para pensar as medidas protetivas de urgência e os serviços de responsabilização para homens autores de violência, valendo-se do que considerou boas práticas em curso no país com os chamados grupos reflexivos de gênero. Nele, faz constar procedimentos, fluxos e rotinas para aplicação e acompanhamento, anexando uma série de modelos de instrumentos de trabalho, como formulários para atendimentos e encaminhamentos, fichas de comparecimento, termos de compromisso etc. Ainda, estabelece critérios para o treinamento das pessoas a atuarem nessas intervenções.

Porém, ainda são poucas as experiências custeadas pelo próprio Ministério da Justiça, a partir dos recursos repassados pelo DEPEN. Entre 2009 e 2014, foram apenas oito propostas, em sete unidades da federação: Acre, Alagoas, Ceará, Mato Grosso do Sul, Pará e Paraná, além do Distrito Federal (Amado, 2014). E, se diante de uma lógica estatal já se encontram dificuldades para seguir as diretrizes institucionais traçadas, quando os projetos são desenvolvidos por outras vias, o controle é ainda mais fragilizado. Como diz um entrevistado: "a gente tem muito boa intenção. Mas, entre boa intenção e aquilo que de fato a gente deseja para combater a violência contra a mulher tem um bom espaço. Vai aí uma distância muito grande." (B4).

Uma das principais preocupações é garantir que os profissionais envolvidos tenham formação ou, ao menos, familiaridade com os estudos 
feministas e de gênero e que essas leituras sejam incorporadas à base metodológica dos serviços, condição primeira para garantir um ideal responsabilizador e não meramente assistencialista. Nesse sentido, ponderam os/as entrevistados/as:

Eu tenho medo dos serviços que não tenham uma (...) que os profissionais não tenham uma qualificação em estudos de gênero, em masculinidade e feminista. Porque o discurso do homem é um discurso extremamente sedutor. A gente acreditar que eles são vítimas é muito fácil. Então, se alguém despreparado pega para conduzir um grupo, ele pode ainda fazer um desserviço para esses homens. (B1).

[...] o que me preocupa muito [...] é que a perspectiva de gênero, trabalhar com gênero, é algo que está passando muito ao largo das respostas que estão sendo dadas. Porque assim como aconteceu com o resto do que está previsto na Lei Maria da Penha, o trabalho com os homens autores de violência está entrando muito mais por uma porta do assistencialismo, de você trazer esses homens para um cuidado. (B4).

Isso também é necessário para garantir que as intervenções não se aproximem da defesa de ideais familistas, fundamentados em uma moralidade cristã restritiva e preconceituosa, que ao pregar a sacralidade do matrimônio pode dificultar o reconhecimento da violência contra as mulheres como uma grave violação de direitos humanos. É o que se observa nas falas seguintes:

Quem está fazendo essa reabilitação? Quem são essas pessoas? Tem um treinamento certo para fazer? Não tem que eu saiba, né? Eu conheci algumas pessoas que são juízas, que elas vão lá e vêm com uma coisa toda de família cristã. Pelo amor das deusas! E aí que a minha preocupação: quem está fazendo? Essas pessoas têm competência para fazer uma coisa que seja uma perspectiva feminista de gênero? Ou que não seja CRISTÃ, entendeu? 
Quem está fazendo em alguns lugares são os evangélicos, cara, que trabalham nas prisões também. Isso que me preocupa. (A1).

[...] os centros de acompanhamento, a maior parte do serviço social é ultra, ultra pró-família. Pró-família significa que tudo que importa não é a integridade física ou psíquica da mulher, nem do homem para dizer a verdade. Importa que a família continue junto. Então, paga um preço. A maior parte do serviço social aprende isso. Os centros fazem tudo para que não haja briga. (A2).

Há também preocupações no sentido de que os serviços não assumam uma abordagem meramente cognitivo-comportamental ou terapêutica, pois elas igualmente os afastariam de seu ideal responsabilizador. Essas preocupações são expressas nas falas seguintes:

E ainda acho também que a forma, se o trabalho é feito de forma cognitiva ou comportamental, às vezes também não é das formas mais adequadas. Eu tenho críticas do cognitivo-comportamental também. [...] Quando o homem fica muito nervoso, ele fala para ele sair fora da cena, para ele não agredir. Então, é você ensinar uma conduta para o homem. E às vezes ele não trabalhou o que leva ele à conduta violenta. Então, a gente vem do ponto do reconhecimento da violência, por isso é reflexivo. É se responsabilizar por aqui para não cometer. Não ensinar a não cometer sem pensar no processo que leva à violência. (B1).

Porque se vai nessa linha terapêutica, que geralmente um psicoterapeuta não está julgando, ele está sempre devolvendo a pergunta. Se o paciente lhe pergunta: 'será que eu fiz mal?', um terapeuta treinado em terapia tradicional, para chamar assim, psicanalítico, a resposta geralmente vai ser: ‘não sei. O que o senhor acha? Por que me pergunta? Acha que fez mal?' Em 
uma linha terapêutica é fantástico, agora esses grupos foram criados também para dizer: o Estado cobrou do senhor pelo que você fez. (B5).

Segundo a teoria do "ciclo da violência" (Walker, 1999), a dinâmica da violência doméstica e familiar obedece a um movimento circular e contínuo, composto por três fases. A primeira é caracterizada pela construção da tensão no relacionamento. É quando se verificam os primeiros incidentes, de proporções menores, como agressões verbais, ameaças, deterioração de objetos, ataques de ciúmes e comportamento controlador etc. Nesse momento, via de regra, as mulheres buscam tranquilizar seus parceiros e impedir que a situação se agrave, assumindo muitas vezes a responsabilidade pelos atos de seus companheiros.

A etapa que segue é identificada como a explosão da violência. As agressões são intensificadas, com registro de maus-tratos físicos. A mulher tende a experimentar sentimentos de medo, vergonha, frustração e raiva. Em alguns casos, é quando a mulher decide buscar ajuda com familiares, amigos ou nos órgãos públicos, tentando promover um distanciamento do autor da violência.

Na terceira e última fase, também chamada de "lua de mel", ocorrem o arrependimento e a tentativa de reaproximação por parte do companheiro. Este pode argumentar que seu comportamento não foi premeditado, mas fruto de um descontrole emocional, portanto, perdoável, garantindo que não voltará a agir de maneira violenta. O resultado pode ser a retomada da relação e o ciclo é reiniciado.

Dessa maneira, se os profissionais atuantes nos grupos reflexivos não tiverem formação teórica dos estudos de gênero e compromisso com a responsabilização desses sujeitos, como afirmou um entrevistado, os homens "aproveitam para melhorar seus argumentos. Acabam saindo com mais conhecimento mesmo da sua habilidade verbal e dominam as pessoas em volta pelas habilidades verbais mais apuradas." (B5).

\section{O "PLUS" DA PENA}


Em sua redação original, a lei Maria da Penha não deixou explícito em que momento do processo penal a participação dos homens nos serviços de responsabilização e educação deveria ser imposta ou ofertada. Na forma do art. 35, apresentou os serviços como um direito a ser promovido pela união, estados, municípios e Distrito Federal, na medida de suas competências. Além disso, a enquadrou como uma pena, conforme dispõe o art. 45, que altera a lei de execução penal para garantir ao juiz a possibilidade de determinar o comparecimento obrigatório dos homens autores de violência aos serviços e programas existentes. Recentemente, com a edição da lei $n^{\circ} 13.984 / 2020$, foi também apresentado como medida protetiva de urgência.

Podemos dizer que a legislação, ao menos aparentemente, rompe com algumas referências históricas do conceito dominante de pena ou punição, que é construído a partir de duas distinções fundamentais: punição/reparação e punição/recompensa. O conceito moderno de pena foi construído em oposição ao conceito de recompensa, que comportaria necessariamente uma forma sancionatória negativa, com capacidade de reduzir o bem-estar daquele que incide na prática delituosa. A punição (como oposição à recompensa) exclui a possibilidade de pensar formas menos radicais ou mais positivas de sancionar os indivíduos, como as penas pecuniárias ou as penas alternativas. A possibilidade de interpretar essas penas como recompensa (e não como punição propriamente dita) ilustra essa interpretação de que sua aplicação implica a "descriminalização" ou "despenalização" (Pires \& Cauchie, 2011).

Se a lei Maria da Penha ensaiou promover uma inovação em matéria de direito penal, a partir da previsão do encaminhamento obrigatório dos homens autores de violência para os serviços de responsabilização e educação, a pesquisa empírica nos mostrou que essa inovação não se concretizou, nem do ponto de vista prático nem do ponto de vista cognitivo, ou seja, do ponto de vista do pensamento sobre o tema. E sem uma mudança de concepção "é possível, mas relativamente complicado falar de ideia inovadora quando ela não foi ainda selecionada, quando ela ainda não produziu, no sistema, o efeito de inovação em suas estruturas centrais" (Pires \& Cauchie, 2011, pp. 324-325). 
O conceito de inovação implica resposta diversa daquelas que são ordinariamente empregadas para determinada questão. É "uma resposta que reativa possibilidades que foram institucionalmente excluídas" (Pires \& Cauchie, 2011, p. 300). Dito de outra maneira, inovador é aquilo que desvia de uma estrutura que se assume como central e é tomada como ponto de referência.

Pires e Cauchie (2011) utilizam a lei $n^{\circ}$ 11.343/2006 (lei de drogas) que, na contramão do que se observa na grande parte da legislação penal brasileira (e ocidental), promoveu uma mudança "improvável" em termos de penas. A resposta para quase a totalidade das condutas típicas no Brasil é prisão ou multa. No entanto, de acordo com a redação do seu artigo 28, que tipifica o crime de posse de drogas para uso pessoal, podem ser aplicadas ao infrator penas de advertência, prestação de serviços à comunidade ou medida educativa de comparecimento a programas ou cursos educativos. A prisão, pelo menos aparentemente, é excluída do rol de possibilidades. Assim, as medidas previstas não correspondem de modo pleno à noção de pena que usualmente se emprega na doutrina e política criminal, ou seja, aquelas tendentes a priorizar medidas aflitivas.

[...] há leis criminais que excluem a prisão para selecionar exclusivamente a multa. "Excluir a prisão" não é então um acontecimento tão raro assim. Mas a prisão não cede aqui o seu lugar para a multa. Esta também está ausente. Essa lei ainda tem outros aspectos surpreendentes: ela exclui a prisão e a multa referindo-se a um "crime" no sentido jurídico estrito de uma categoria particularmente grave de infrações criminais (em oposição a uma contravenção ou uma infração administrativa). As penas previstas aqui não são justamente penas clássicas como a multa ou a prisão, mas sim penas que não têm usualmente o status jurídico de penas criminais. Essa seleção pode ser considerada então como "altamente improvável" na prática legislativa ocidental moderna (criação de sanções criminais). (Pires \& Cauchie, 2011, p. 302-303). 
A modificação na lei nos conduz tão somente para uma expectativa generalizada de orientar as decisões judiciais, que pode estimular a aplicação do elemento inovador, mas sem qualquer garantia de que será a solução selecionada pelo sistema de justiça criminal. Inclusive porque, a rigor do art. 27 da lei de drogas, as penas ali previstas podem ser aplicadas de maneira isolada ou cumulativamente, bem como substituídas a qualquer tempo, desde que ouvidos o Ministério Público e a defesa. Isto abre certa margem de discricionariedade ao julgador. Ele tanto pode assumir uma postura de reproduzir a norma em sentido literal, como ainda propor outras sanções como as previstas no artigo 28 para outros crimes (Pires \& Cauchie, 2011).

$\mathrm{Na}$ fala das/os interlocutoras/es e com apoio nos documentos pesquisados, - modelo tradicional de punição ainda é o referencial central para o seu enfrentamento, constituindo a participação nos serviços uma espécie de "plus da pena" - expressão retirada de uma entrevista - para alcançar aquilo que a prisão por si só se mostrou incapaz.

O documento elaborado pela SPM/PR no intuito de traçar as diretrizes gerais dos serviços faz constar expressamente que este se presta ao objetivo precípuo de promover "o acompanhamento das penas e decisões proferidas pelo juízo competente no que tange ao agressor." Na síntese das discussões desenvolvidas no evento que culminou na sua elaboração, registram-se falas como: "há um crime que precisa ser punido"; "o centro é elemento de educação e não de punição", de modo que o encaminhamento dos homens ao serviço não é visto como a pena em si, mas apenas um complemento. Para ser pena, precisa carregar caráter negativo, dissociada de qualquer perspectiva de ganho ou recompensa para quem atentou contra a norma penal. Até é admissível uma intervenção positiva, desde que ela não elimine a imposição de uma pena aflitiva.

Então, a lei Maria da Penha ela vai incluir duas situações: primeiro, durante o processo, já se oferece à vítima, aos seus familiares e ao autor da agressão, o acesso a um atendimento psicossocial; e, depois da condenação, o juiz pode aplicar uma pena, um plus da pena, seja pena restritiva de direitos, seja pena 
restritiva de liberdade, o juiz pode aplicar um plus que é a obrigatoriedade desse autor da violência de participar desses grupos de reeducação, o nome que a lei dá ou que foi depois utilizado como responsabilização dos homens autores de violência. (A5).

Assim, a proposição contida na lei Maria da Penha "está mais para uma ideia alternativa, para um ponto potencial de bifurcação que é apenas potencialmente inovador" (Pires \& Cauchie, 2011, p. 325), mas que ainda não conseguiu ser operacionalizada na prática, pois não se rompeu com as barreiras impostas pelas teorias tradicionais da pena, criando um "obstáculo epistemológico" (Pires, 1999) à implementação desses serviços. Ou seja, um modo de pensar que é próprio da cultura jurídica dos séculos XVIII e XIX, ainda percebido por alguns atores sociais como sinais de avanço, mas que também representa um tipo de recuo ou barreira para a implementação do processo de humanização e atualização do direito (Pires, 2019).

\section{CONSIDERAÇÕES FINAIS}

Os estudos no campo da violência contra as mulheres e, sobretudo, aqueles que problematizam a eficácia da lei Maria da Penha têm mostrado que a resposta penal ainda é a resposta central se comparada com as medidas assistenciais e preventivas ${ }^{7}$. Alguns setores dos grupos feministas rejeitam as punições não prisionais - por entender que a criminalização da violência baseada no gênero e sua punição com pena de prisão é requisito simbólico fundamental, de modo que seria impossível dissociar esta questão social do seu tratamento pelo sistema de justiça criminal (Sinhoretto \& Tonche, 2019).

No entanto, se num momento anterior se acreditou ser importante investir no recrudescimento da punição, a fim de afastar a possibilidade de banalização ou naturalização da violência contra as mulheres, esse discurso hoje se coloca como barreira à consolidação de novas possibilidades de enfrentamento.

\footnotetext{
${ }^{7}$ Ver, por exemplo, Campos (2015) e Pasinato (2015).
} 
Como aparece nas falas dos nossas/os interlocutoras/es, a violência contra as mulheres, principalmente quando ocorrida em contexto doméstico e familiar, não segue necessariamente um fluxo linear. Ao contrário, opera em ciclos ou fases que incluem momentos de crise e reconciliação, nem sempre racionalizáveis como pressupõe nosso sistema de justiça clássico, marcado por seus binarismos e simplificações (Sinhoretto \& Tonche, 2019).

As falas sugerem que as intervenções junto a homens autores de violência, ao apostarem nas reflexões sobre as relações de gênero e exercício das masculinidades, podem funcionar como uma das peças dessa engrenagem, auxiliando esses sujeitos na construção de alternativas não violentas para a resolução de seus conflitos interpessoais. Todavia, não basta ressaltar sua importância, é preciso fazer efetivamente a disputa na esfera pública.

Criar as condições necessárias para progredir diante do atual campo político não será fácil. Não conseguimos avançar suficientemente em termos da implementação desses serviços nos últimos anos e o que se espera dos tempos vindouros é ainda menos promissor, tendo em vista o avanço do conservadorismo e o cenário de desmonte das políticas públicas de gênero. Será já um grande desafio se manter o pouco que se conseguiu avançar. Neste contexto, as mobilizações coletivas de homens em apoio às reivindicações dos feminismos, bem como a ação dos próprios movimentos feministas e de mulheres são, mais do que nunca, mecanismos fundamentais para a consolidação de uma política pública nacional e integrada de intervenção junto a homens autores de violência contra as mulheres.

\section{REFERÊNCIAS}

\section{Acosta, f., Andrade Filho, A., \& Bronz, A. (2004). Conversas homem a homem: grupo reflexivo de gênero. Rio de janeiro: Instituto Noos.}

\section{Adorno, S. \& Bordini, E. (1989). Reincidência e reincidentes penitenciários e São Paulo, 1974-1985. Revista Brasileira de Ciências Sociais, 9 (3), 70-94.}


Adorno, S. \& Bordini, E. (1991). A socialização na delinquência: reincidentes penitenciários em São Paulo. São Paulo: NEV-USP.

Amado, R. M. (2014). Os serviços de educação e responsabilização para homens autores de violência contra as mulheres: uma análise de quadros interpretativos, modelos de intervenção e atores. [Dissertação de Mestrado, Programa de Pós-graduação em Sociologia, Universidade de Coimbra].

Andrade, V. R. P. de. (1999). Criminologia e feminismo: da mulher como vítima à mulher como sujeito de construção da cidadania. In C. H. de Campos (Org.), Criminologia e feminismo (p. 105-117).

Andrade, L. F. (2014). Grupos de homens e homens em grupos: novas dimensões e condições para as masculinidades. In E. A. Blay (Org.), Feminismos e masculinidades: novos caminhos para enfrentar a violência contra a mulher (p. 173-209).

Andrade, L. F. \& Barbosa, S. F. (2008, 25 a 28 de agosto). A Lei Maria da Penha e a implementação do grupo de reflexão para homens autores de violência contra mulheres em São Paulo. [Apresentação de trabalho]. Anais do Seminário Internacional Fazendo Gênero 8. Universidade Federal de Santa Catarina.

Baratta, A. (2011). Criminologia crítica e crítica do direito penal: introdução à sociologia do direito penal. Rio de Janeiro: Revan.

Beiras, A., Nascimento, M., \& Incrocci, C. (2019). Programas de atenção a homens autores de violência contra as mulheres: um panorama das intervenções no Brasil. Revista Saúde e Sociedade, 28(7), 262-274. https://doi.org/10.1590/s0104-12902019170995

Calazans, M., \& Cortes, I. (2011). O processo de criação, aprovação e implementação da Lei Maria da Penha. In C. H. de. Campos (Org.), Lei Maria da Penha comentada em uma perspectiva jurídico-feminista (p. 39-64).

Câmara dos Deputados. (2009). CPI sistema carcerário.

Campos, C. H. de. (2015). Desafios na implementação da Lei Maria da Penha. Revista Direito GV, 17(2), 391-406. https://doi.org/10.1590/1808-2432201517

Connell, R. (2016). Gênero em termos reais. São Paulo: nVersos.

Cortês, I. R. \& Matos, M. C. de. (2009). Lei Maria da Penha- do papel para a vida: comentários à Lei 71.340/2006 e sua inclusão no ciclo orçamentário. Brasília: CFEMEA. 
Departamento Penitenciário Nacional. (2016). Manual de gestão para alternativas penais: medidas protetivas de urgência e demais serviços de responsabilização para homens autores de violências contra as mulheres - procedimentos, fluxos e rotinas para aplicação e acompanhamento.

Fórum Brasileiro de Segurança Pública \& Datafolha. (2019). Visível e invisível: a vitimização de mulheres no Brasil.

Instituto de Estudos da Religião. (2012). Documento base para a elaboração de parâmetros técnicos para os serviços de educação e responsabilização de homens autores de violência doméstica contra mulheres.

Instituto de Pesquisa Econômica Aplicada. (2015). Reincidência criminal no Brasil.

Jong, L. C., Sadala, M. L. A. \& Tanaka, A. C. D. (2008). Desistindo da denúncia ao agressor: relato de mulheres vítima de violência doméstica. Rev. Esc. Enferm. USP, 42(4), 744-751. https://doi.org/10.1590/s008062342008000400018

Kahn, T. (2001). Além das grades: radiografia e alternativas ao sistema prisional. São Paulo: Mimeografado.

Lemgruber, J. (1989). Reincidência e reincidentes penitenciários no sistema penal do Estado do Rio de Janeiro. Revista da Escola de Serviço Penitenciário do Rio Grande do Sul, 7(2), 45-76.

Ministério da Justiça. (2015). Violência contra a mulher e as práticas institucionais.

Mourão, B. M. (2014). Violência contra a mulher: conceito válido? In R. S. de Lima, J. L. Ratton, R. G. de Azevedo (Org.), Crime, polícia e justiça no Brasil (p. 285292).

Oliveira, A. E. C. de. (2012). Atendimento a homens autores de violência contra a mulher: lacunas, desafios e perspectivas. [Dissertação de Mestrado, Programa de Pós-graduação em Estudos Interdisciplinares sobre Mulheres, Gênero e Feminismo, Universidade Federal da Bahia].

Pasinato, W. (2015). Oito anos de Lei Maria da Penha. Entre avanços, obstáculos e desafios. Revista Estudos Feministas, 23(3), 533-545. https://doi.org/10.1590/0104-026X2015v23n2p533

Pires, Á. (1999). Alguns obstáculos a uma mutação "humanista" do direito penal. Revista Sociologias, 7(1), 64-95. 
Pires; Á. \& Cauchie, J. (2017). Um caso de inovação "acidental" em matéria de penas: a lei brasileira de drogas. Revista Direito GV, 7(7), 299-330. https://doi.org/10.1590/S1808-24322011000100015

Salla, F. \& Lourenço, L. C. (2014). Aprisionamento e prisões. In R. S. de Lima, J. L. Ratton \& R. G. de Azevedo (Org.), Crime, polícia e justiça no Brasil (p. 376381).

Sapori, L. F., Santos, R. F. \& Maas, L. W. D. (2017). Fatores sociais determinantes da reincidência criminal no Brasil: o caso de Minas Gerais. Revista Brasileira de Ciências Sociais, 32(94), 1-18. https://doi.org/10.17666/329409/2017

Secretaria de Política para as Mulheres da Presidência da República. (2011). Diretrizes gerais dos serviços de responsabilização e educação do agressor.

Sinhoretto, J. \& Tonche, J. (2019). Justiça restaurativa para os direitos das mulheres. In P. Carlen, L. A. França (Org.), Alternativas à justiça (s.p.).

Souza, C. G. M. (2017). Retratação na Lei Maria da Penha: um estudo psicossocial. [Dissertação de Mestrado, Programa de Pós-graduação em Psicologia, Universidade Federal de Alagoas].

Souza, L. C. G. de \& Vera, F. S. (2010). Orçamento da União: instrumento para a igualdade de gênero e para o desenvolvimento. In F. B. Meneguin (Org.), Agenda legislativa para o desenvolvimento nacional (p. 343-356).

Taylor, A. \& Barker, G. (2013). Programs for men who have used violence against women: recommendations for action and caution. Rio de Janeiro: Instituto Promundo.

Teixeira, M. S. \& Maia, M. (2011). Avaliação do projeto paz em casa, paz no mundo a partir dos seus beneficiários. Rio de Janeiro: Instituto Noss.

Vieira, C., Cabral, G. \& Oliveira, G. (2014). Orçamento Mulher: uma história de 12 anos de incidência política do CFEMEA. Brasília: CFEMEA.

Walker, L. E. (1999). The battered woman syndrome. New York: Springer Publishing Company.

'Anderson Eduardo Carvalho de Oliveira: Doutor e mestre em Estudos Interdisciplinares sobre Mulheres, Gênero e Feminismo pela Universidade Federal 
da Bahia (UFBA). Licenciado em Ciências Sociais pela Universidade Federal da Bahia (UFBA). Bacharel em Direito pela Faculdade de Alagoas (FAL). Pesquisador Associado do Núcleo de Estudos Interdisciplinares sobre a Mulher (NEIM/UFBA). Professor associado do Centro Universitário UniFTC..

iiMariana Thorstensen Possas: Doutora em Criminologia pela Universidade de Ottawa. Professora do Departamento de Sociologia e do Programa de PósGraduação em Ciências Sociais da Universidade Federal da Bahia..

Data de submissão: 16/01/2021.

Data de aprovação: 15/04/2021. 